\title{
貯槽内微粉体の粉体圧に関する研究
}

\author{
永徳 久 登*, 廣田 満 昭*, 鈴木 道 隆*, 大島 敏 男*
}

\section{A Study of the Pressure of a Fine Powder in a Bin}

by

\author{
Hisato EITOKU ${ }^{\dagger}$, Mitsuaki HIROTA ${ }^{\dagger}$, Michitaka SUZUKI ${ }^{\dagger}$, \\ and Toshio OSHIMA ${ }^{\dagger}$
}

\begin{abstract}
Janssen's equation is applied to estimate the pressure of the fine powder contained in a bin. In the storage of fine powder, the void fraction varies with the depth of the bed. The mechanical properties of the bed, such as cohesions and the ratio of the horizontal stress to the vertical stress, depend on the void fraction of the bed. To estimate a powder pressure using Janssen's equation, these mechanical properties are expressed as a function of the major principal stress acting on the bed. Powder pressures are calculated for the bed conditions of both plastic equilibrium and dynamic friction. Experimental results show that the powder pressures are in the range of the estimated values.
\end{abstract}

\footnotetext{
Key Words : Janssen's Equation, Distribution of Powder Pressure, Compressive Property, Shear Properties, Dynamic Friction Coefficient
}

\section{1. 緒言}

貯槽内の粉体圧に関する研究はかなり以前から行な われており，数多くの理論と実験結果が報告されてい $3^{1 \sim 3)}$ 。しかし, 取り扱う粉体が微粉体の場合, 実際 の粉体圧は理論式で算出した值とかなり異なる場合が ある。これは, 粉体物性(かさ密度, 応力比など)の圧 力依存性が大きいためと考えられる。すなわち，微粉 体の貯槽においては, 層下部の粉体は上部粉体によっ て圧密され，高さ方向に充てん率分布を持つため, 物 性值を首全体で一定として取り扱うことはできない。 また，層内の応力状態も必ずしも限界状態にあるとは いえないが,これらを考虑した粉体圧の研究は極めて 少ない。そこで本報では, 粒状材料の静的粉体圧を算

\footnotetext{
1994年 3月 7日 受付

第31回粉体に関する討論会(1993年10月, 神戸)にて一部発表

* 姬路工業大学工学部産業機械工学料

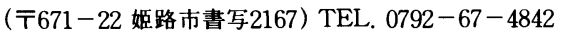

† Dept. of Chem. Eng., Faculty of Eng., Himeji Inst.

Technol., (2167 Shosha, Himeji, 671-22)
}

出する理論式として広く用いられているJanssen式を もとに, 先に述べた点を考慮して, 粉体の物性試験結 果から微粉体層の粉体圧の算出を試み, 実験值との比 較検討を行なった。

\section{2. 試料粉体および物性試験}

\section{1 試料粉体}

試料粉体として, 流動性の良いフライアッシュと, 流動性の悪い微粉体のシリカおよび軽質炭酸カルシウ ムの 3 種類を用いた。これら試料粉体の $50 \%$ 粒径なら びに粒子密度とゆるみかさ密度をTable 1に示した。

Table $150 \%$ Particle diameter, particle density and aerated bulk density of sample powders

\begin{tabular}{lccc}
\hline $\begin{array}{l}\text { Sample } \\
\text { powder }\end{array}$ & $\begin{array}{c}50 \% \text { Particle } \\
\text { diameter } D_{50}(\mu \mathrm{m})\end{array}$ & $\begin{array}{c}\text { Particle density } \\
\rho_{\mathrm{p}}\left(\mathrm{kg} / \mathrm{m}^{3}\right)\end{array}$ & $\begin{array}{c}\text { Aerated bulk } \\
\text { density } \rho_{\mathrm{B}}\left(\mathrm{kg} / \mathrm{m}^{3}\right)\end{array}$ \\
\hline Flyash & 13.2 & 2320 & 928 \\
Silica & 3.2 & 2650 & 461 \\
$\mathrm{CaCO}_{3}$ & 3.6 & 2550 & 291 \\
\hline
\end{tabular}




\section{2 物性試験}

\section{2. 1 世ん断試験}

平行平板型のせん断試験機を用いて各試料粉体のせ ん断試験を行なった。Fig. 1は所定の圧密応力 $\sigma_{1}$ で 予圧密後, せん断時の圧縮応力 $\sigma\left(<\sigma_{1}\right)$ でせん断を行 ったときのせん断応力 $\tau$ とせん断ひずみ $\Delta s$ との関係 の概念を示したものである ${ }^{4)} 。 \tau$ は $\mathrm{P}$ 点 $\left(\tau=\tau_{\mathrm{p}}\right)$ に達

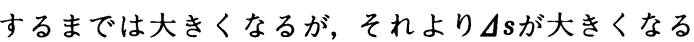
と, 逆に減少し, C点に至る。 $\mathrm{P}$ 点は粉体首の任意の 面でまさにすべり崩壊が起ころうとしている応力状態 （以下，限界応力状態と呼ぶ）であり， $\sigma\left(<\sigma_{1}\right)$ に对して 䄈をプロットすることによって，破壊包絡線(powder yield locus, 略してPYL)が得られる。また，C点の 状態は, せん断応力は一定 $\left(=\tau_{\mathrm{c}}\right)$ で $\Delta s$ だけが増加す る，いわゆる定常すべり状態であり， $\sigma\left(<\sigma_{1}\right)$ に对して 䄈をプロットすることによって, 粒子一粒子間の限界状 態線 (critical state line, 略してCSL)が得られる。 PYLから粉体層の内部摩擦角 $\phi_{\mathrm{i}}$ とせん断付着力 $($ 粘着 力) $C_{\mathrm{i}}$ が求められる。また, CSLから層の動摩擦角 $\delta$ を求めることができる。以上は粒子層内部の崩壊であ るが，粒子と壁面間の崩壊を扱えば壁面破壊包絡線 (wall yield locus，略してWYL)および粒子-壁面間 の限界状態線が得られる。それらの結果から, 粒子一 壁面間の粘着力 $C_{\mathrm{w}}$, 壁面摩擦係数 $\mu_{\mathrm{ws}}\left(=\tan \phi_{\mathrm{w}}\right)$ およ び壁面動摩擦係数 $\mu_{\mathrm{wd}}\left(=\tan \delta_{\mathrm{w}}\right)$ が求められる。

Fig. 2にシリカのPYLを示す。PYLは僅かに上に 凸の曲線になるが，ほぼ直線で近似でき，内部摩擦角 $\phi_{\mathrm{i}}$ は予圧密時の最大主応力 $\sigma_{1}$ によらずほぼ一定にな る。しかし，綎軸の切片として得られる粒子間のせん 断付着力 $C_{\mathrm{i}}$ は $\sigma_{1}$ の增加に伴って大きくなる。

ここでは示してないが,WYLもPYLと同じ傾向が みられ，壁面摩擦係数 $\mu_{\mathrm{ws}}$ は $\sigma_{1}$ に依存しないが, 粒子一 壁面間のせん断付着力 $C_{\mathrm{w}}$ は $\sigma_{1}$ に依存する。

Fig. 3に各試料粉体についての粉体首の限界状態線

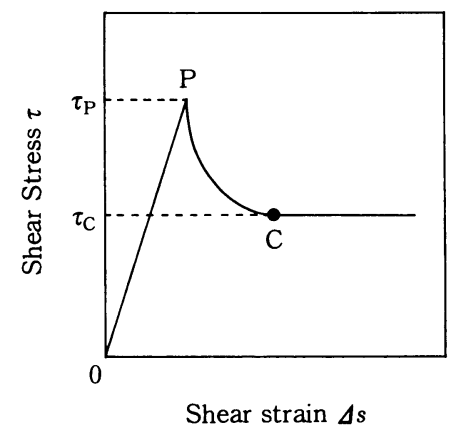

Fig. 1 Conceptual diagram of shear process

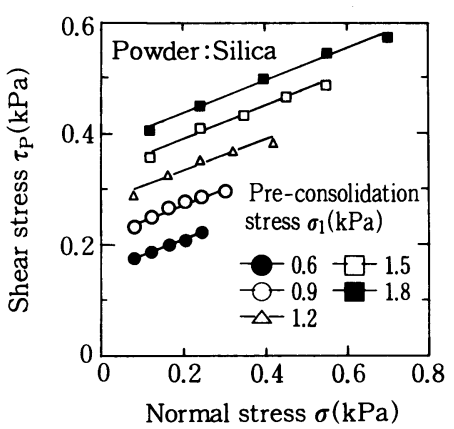

Fig. 2 PYL of sample powder

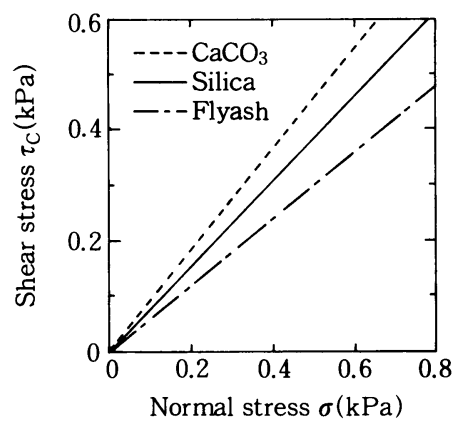

Fig. 3 CSL of sample powders

(CSL)を示す。粒子間のCSLは予圧密応力 $\sigma_{1}$ によら ず原点を通る一本の直線となる。よって, 内部動摩擦 角 $\delta_{\mathrm{i}}$ は層の $\sigma_{1}$ によらず, 試料固有の值を持ち, また, $C_{\mathrm{i}}=0$ になる。

同様に，粒子一壁面間の動摩擦角 $\delta_{\mathrm{w}}$ も $\sigma_{1}$ に依存せず， 試料および壁面材質により決る固有の值を持ち，ま た, $C_{\mathrm{w}}=0$ になる。

\section{2.2 圧縮試験結果}

Fig. 4に粉体首の圧縮試験結果を示した。Table 1に示したように,これらの試料の粒子密度の差は小 さいが, かさ密度はかなり異なる。また，付着性の強 い微粉ほど, かさ密度の值は小さく, 垂直荷重の増加

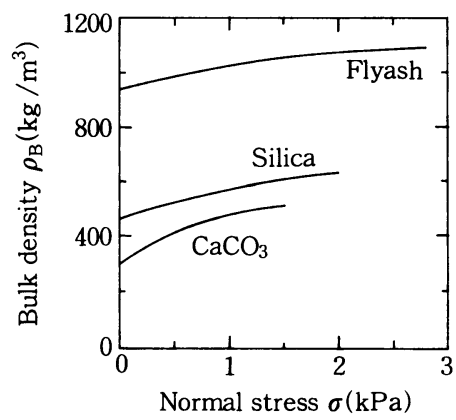

Fig. 4 Relation between bulk density and normal stress 


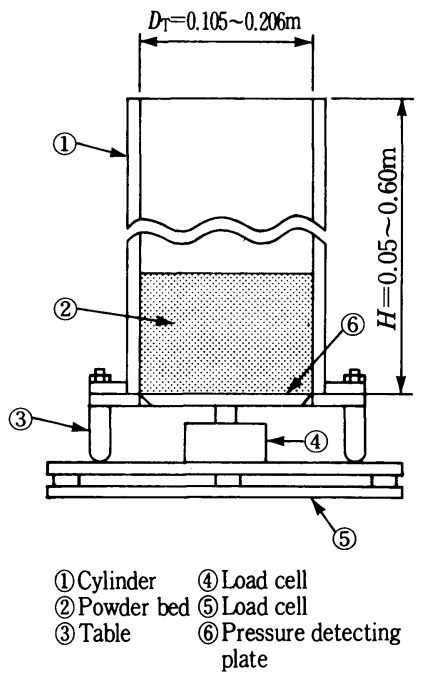

Fig. 5 Schematic diagram of apparatus

に伴うかさ密度の変化の割合も大きい。

\section{3. 実験装置および方法}

Fig. 5に実験装置の概略を示す。円筒容器 (1) に試 料粉体をふるいを通して, 粉体層表面が平らになるよ うに充てんしたときの粉体首の底面圧をロードセル (4)により連続的に測定した。この時，充てん速度をほ ぼ一定にするため, 試料によりふるいの目開きを変え

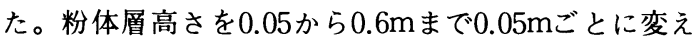
て, 各々の粉体層高さでの底面圧を測定し，粉体首の 高さ方向の圧分布を求めた。また同時に，投入粉体の 重量もロードセル (5)で測定し，層の高さ方向のかさ 密度の分布も求めた。

円筒容器として, 内径 $0.105,0.140$ おび $0.206 \mathrm{~m} の$ 3 種類の透明アクリルパイプを使用した。

\section{4. 実験結果および考察}

\section{1 粉体圧測定}

Fig. 6に, 各試料粉体の充てん時間(充てん量に対 応している)に对する底面圧の変化の例を示す。首高 さがある程度以上に高くなると，圧力に変動が見られ るようになる。このことから，首上部の粉体圧によっ て下部層が崩壊し, 圧密されることが分かる。しか し, 圧力変動の様子は試料によりかなり異なる。流動 性の悪い軽質炭酸カルシウムやシリカの場合, 圧力の 変動幅が小さいことより, 層の圧密は連続的に起こっ ているものと考えられる。これは，付着性が強いの で, 層の充てん構造が非常に不均質になり, 首全体に

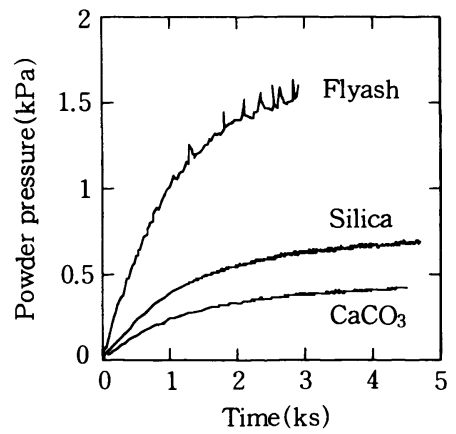

Fig. 6 Relation between powder pressure and packing time

わたって局部的な圧密が頻繁に起るためと考えられる。 これに対して，流動性の良いフライアッシュでは比較 的大きな変動のピークが断続的に発生する。これは, フライアッシュは流動性が良いために粒子は均質な粉 体層を形成する。そのため, 首上部の粉体圧によって 層下部が崩壊するとき，かなり広い領域で同時に動摩 摖状態になるので，低面圧は高くなる。しかし，動摩 擦力と底面圧が粉体の重量と釣り合ったとき，層は再 び静止し，静摩擦状態になるので，底面圧は低下す る。この現象が繰り返されるために断続的にピークが 現れると考えられる。

一般に，理論式で粉体圧を算出する場合には，首全 体が限界応力状態であると仮定している。しかし, 微 粉体のように粉体層の圧密が起こる場合, 粉体圧によ り首が崩壊する直前では首全体は最大静止摩擦により 釣り合うが, 崩壊した後, 動き出した粒子は, 動摩擦 の状態で釣り合って再び静止する。このように考える と垂直方向の粉体圧は層全体が最大静止摩擦により釣 り合うときに最小となり，動的に釣り合う場合に最大 となるはずである。しかし，首全体が同時に限界応力 状態になる可能性は小さく，また，層全体が同時に動 摩擦状態になることもない。そのため, 粉体圧はこれ ら両者の間になるものと考えられる。よって, 微粉体 層の粉体圧は，単に限界応力状態だけで一義的に決る ものではなく，釣り合いの条件により変化すると考え た方が良い。

そこで, Janssen式により粉体圧を求める際には, 粒子一粒子間ならびに粒子一壁面間における応力状態を 限界状態とする場合，および動摩擦状態とする場合の 両方について算出した。

\section{2 粉体圧の算出}

以下に，付着性粉体におけるJanssen式を示す。 


$$
\begin{aligned}
P= & \frac{\left(\rho_{\mathrm{B}} g D_{\mathrm{T}}-4 C_{\mathrm{w}}\right)}{4 \mu_{\mathrm{w}} k}\left\{1-\exp \left(-\frac{4 \mu_{\mathrm{w}} k}{D_{\mathrm{T}}} h\right)\right\} \\
& +P_{0} \exp \left(-\frac{4 \mu_{\mathrm{w}} k}{D_{\mathrm{T}}} h\right)
\end{aligned}
$$

ここで, $P$ は垂直方向の圧力, $h$ は自由表面からの首 深さ, $P_{0}$ は $h=0$ での垂直圧力, $\rho_{\mathrm{B}}$ はかさ密度, $D_{\mathrm{T}}$ は 容器の内径, $C_{\mathrm{w}}$ は粒子-壁面間のせん断付着力 $($ 粘着 力), $\mu_{\mathrm{w}}$ は壁面摩擦係数である。kは圧力比(垂直方向 の圧力に对する水平方向の圧力の比)であり, いくつ かの式があるが，以下に示すように限界応力状態を仮 定する場合，PYLをもとにした $k_{1}$ を用い，動的状態で はCSLをもとにした $k_{2}$ 用いた。

$$
\begin{aligned}
& k_{1}=\left(\frac{1-\sin \phi_{\mathrm{i}}}{1+\sin \phi_{\mathrm{i}}}\right)\left(1+\frac{C_{\mathrm{i}} \cot \phi_{\mathrm{i}}}{\sigma_{1}}\right)-\frac{C_{\mathrm{i}} \cot \phi_{\mathrm{i}}}{\sigma_{1}} \\
& k_{2}=\frac{1-\sin \delta_{\mathrm{i}}}{1+\sin \delta_{\mathrm{i}}}
\end{aligned}
$$

ここで， $\sigma_{1}$ は最大主応力であるが，貯槽内の最大主 応力の方向はほぼ垂直方向に等しいので, 垂直圧力 Pを用いた。

また， $k_{1}$ 用いて粉体圧を算出する場合は壁面摩擦 係数として静摩擦係数 $\mu_{\mathrm{ws}}\left(=\tan \phi_{\mathrm{w}}\right)$ を用いた。一方, $k_{2}$ を用いる場合，粉体一壁面間の摩擦力を求めるとき

\section{も動摩擦係数 $\mu_{\mathrm{wd}}\left(=\tan \delta_{\mathrm{w}}\right)$ を用いた。}

前述のように，微粉体首では物性值の圧力依存性が 大きいために，物性値を一定として扱うことができな い。特に, かさ密度は圧力により大きく変わるので, 粉体層の深さ方向の圧力変化に応じた值を適用する必 要がある。そこで, Janssen 式の基になっている微分 方程式を差分の形で表し，物性值を粉体圧の関数とし て与えることで数值的に解く方法 ${ }^{5)}$ が試みられている。 ここでは，その考え方をもとに，粒子-壁面間の粘着力 $C_{\mathrm{w}}$ $\sigma_{1}$ に依存することを考㦄に入れて計算を行った。

まず，粉体のかさ密度変化を粉体層の圧縮試験結果 から推定して粉体圧が計算できるかを検討する。

Fig.7に粉体首のかさ密度分布の測定結果，および 実測した粉体圧を粉体層の圧縮試験結果に入れて求め たかさ密度分布の計算結果を示す。フライアッシュの 場合, 両者はよい一致を示しているが, シリカ, 軽質 炭酸カルシウムの順にその相違は大きくなる傾向が認 められる。これは, 円筒容器内の粉体層の場合, 高さ 方向だけでなく半径方向にも圧分布が生じること，お よび充てん率の圧力依存性が付着性の高い粉体ほど大

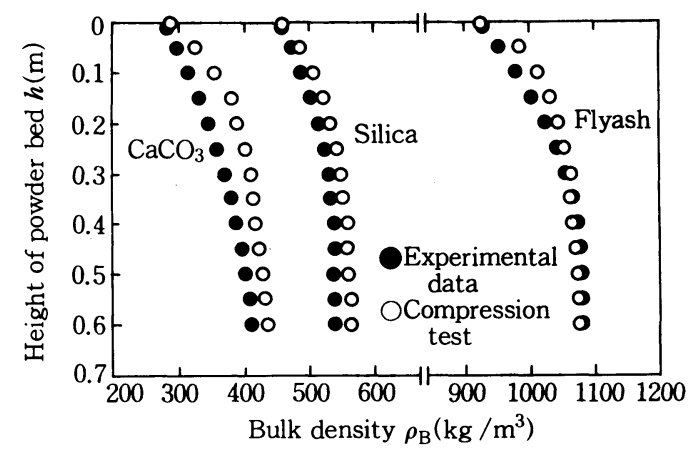

Fig. 7 Relation between height of powder bed and bulk density

きくなるためと考えられる。しかし，どの試料につい ても計算結果は十分適応できる範囲内にある。そこ で, 粉体層の物性試験(圧縮試験およびせん断試験)だ けからJanssen 式により層内の高さ方向の粉体圧分布 を計算する場合(以下，理論值と呼ぶ）と，実測したか さ密度分布とせん断試験結果から圧分布を計算する場 合(以下, 半理論值と呼ぶ)の 2 通りの結果を実測值と 比較検討してみた。

Figs. 8〜10に筒径 $0.140 \mathrm{~m}$ の場合の各試料粉体につ いての粉体圧分布の実測值ならびに計算結果を示し た。

フライアッシュの場合， $k_{1}$ または $k_{2}$ 用いて計算し た結果は, 理論値と半理論値が互いによく一致してい

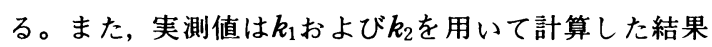
の範囲内に納まっている。他の二つの試料の場合もつ

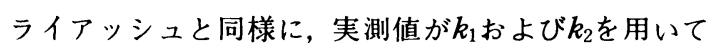
計算した結果の範囲内に納まっている。しかし，理論 値と半理論值の相違は粉体の付着性の高いものほど大 きくなる傾向が認められる。これは，Fig.7に示した ように, 圧縮試験から得られたかさ密度が, 実測した かさ密度よりも大きいためであり, その原因について は前述の通りである。ただし, 図中の粉体圧の実測值 は, 容器への粉体の充てん速度が遅い場合の結果であ ク, 充てん速度によって投入粉体量も幾分違うので, 粉体圧もそれに応じて異なってくるものと考えられる。

Table 2に，粉体層高さが $0.6 \mathrm{~m} の$ ときの底面圧およ び投入粉体量の理論值の結果と実測值を示した。ただ し, フライアッシュの容器径 $0.206 \mathrm{~m}$ の場合について は底面圧が使用したロードセルの許容範囲を越えるの で実験は省略した。粉体層内の高さ方向の圧力分布に ついては, 容器の径や粉体の種類によらず, ほとんど の場合， $k_{1}$ と $k_{2}$ を用いて計算したそれぞれの理論値の 範囲内に納まった。 
Table 2 Powder pressures and charges of sample powders

\begin{tabular}{|c|c|c|c|c|c|c|c|}
\hline \multirow[b]{2}{*}{ Sample } & \multirow{2}{*}{$\begin{array}{c}D_{\mathrm{T}} \\
(\mathrm{m})\end{array}$} & \multicolumn{3}{|c|}{ Powder pressure $(\mathrm{kPa})$} & \multicolumn{3}{|c|}{ Charge $(\mathrm{kg})$} \\
\hline & & $\begin{array}{c}\text { Experimental } \\
\text { data }\end{array}$ & $\begin{array}{l}\text { Static } \\
\text { friction }\end{array}$ & $\begin{array}{c}\text { Dynamic } \\
\text { friction }\end{array}$ & $\begin{array}{c}\text { Experimental } \\
\text { data }\end{array}$ & $\begin{array}{l}\text { Static } \\
\text { friction }\end{array}$ & $\begin{array}{c}\text { Dynamic } \\
\text { friction }\end{array}$ \\
\hline \multirow{2}{*}{ Flyash } & 0.105 & 1.81 & 1.38 & 2.16 & 5.33 & 5.36 & 5.44 \\
\hline & 0.140 & 2.13 & 1.79 & 2.69 & 9.60 & 9.61 & 9.73 \\
\hline \multirow{3}{*}{ Silica } & 0.105 & 0.70 & 0.58 & 0.90 & 2.63 & 2.67 & 2.76 \\
\hline & 0.140 & 1.00 & 0.77 & 1.17 & 4.80 & 4.85 & 5.01 \\
\hline & 0.206 & 1.41 & 1.11 & 1.58 & 11.3 & 10.8 & 11.1 \\
\hline \multirow{3}{*}{$\mathrm{CaCO}_{3}$} & 0.105 & 0.42 & 0.40 & 0.81 & 1.76 & 1.90 & 2.11 \\
\hline & 0.140 & 0.68 & 0.57 & 1.04 & 3.34 & 3.55 & 3.87 \\
\hline & 0.206 & 0.76 & 0.85 & 1.37 & 7.32 & 8.13 & 8.65 \\
\hline
\end{tabular}

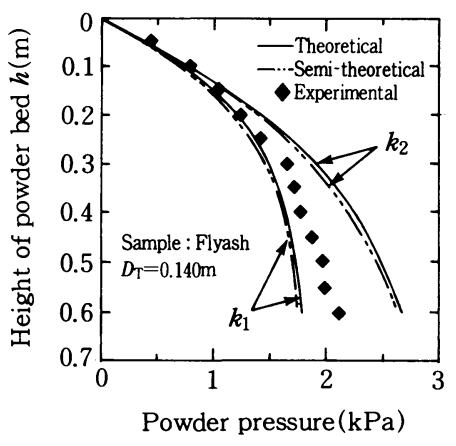

Fig. 8 Relation between height of powder bed and powder pressure

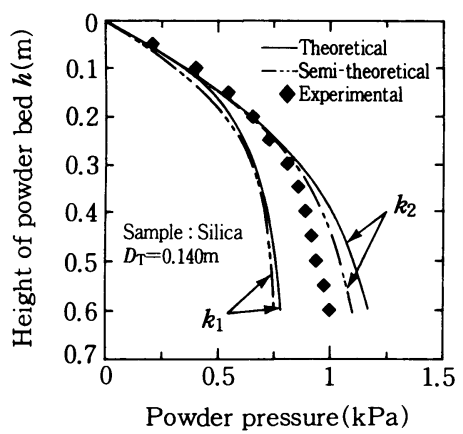

Fig. 9 Relation between height of powder bed and powder pressure

一方，投入粉体量については， $k_{1}, k_{2}$ を用いて計算 した理論值の範囲から外れ， $k_{1}$ から求めた值よりも僅 かに小さくなる傾向が認められた。しかし，付着性の 強い軽質炭酸カルシウムで筒径の大きい場合に, 理論

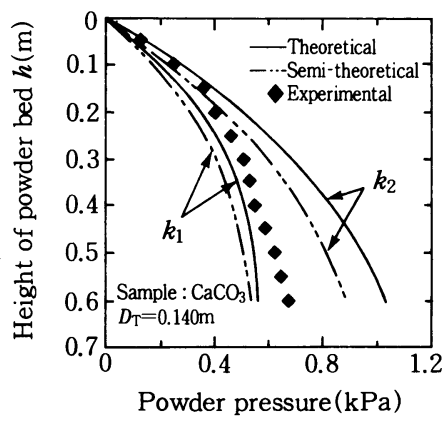

Fig. 10 Relation between height of powder bed and powder pressure

値よりもかなり小さくなることを除いては, 理論値と の相違は比較的小さかった。したがって, 微粉体の貯 槽において, その底面圧力および投入粉体量は物性試 験結果のみから, Janssen 式に基づいて計算した理論 值により推定可能であることが分かる。

\section{5. 結 言}

円筒容器を用いて微粉体の充てん実験を行なった。 微粉体層の粉体圧は, 粉体層の高さ方向における物性 変化を考虑し, また, 限界応力状態および動摩擦状態 に対応する物性値を用いれば，本実験範囲(容器内径 0.105〜0.206m)において, Janssen 式をもとに算出し たそれぞれの理論値の範囲内に納まる。

また, 投入粉体量についても, ほぼ推定が可能であ るが, 理論值は実測值よりも幾分大きくなる傾向が見 られ, 今後, 更に検討する必要があると思われる。

\section{Nomenclature}

$C_{\mathrm{i}}$ : particle-particle cohesion

$C_{\mathrm{w}}:$ particle-wall cohesion

$D_{50}: 50 \%$ particle diameter

$D_{\mathrm{T}}:$ diameter of vessel
$(\mathrm{kPa})$

$(\mathrm{kPa})$

$(\mu \mathrm{m})$

(m) $g$ : gravitational acceleration

$H$ : height of powder bed

$\left(\mathrm{m} / \mathrm{s}^{2}\right)$

$(\mathrm{m})$

$h$ : depth from free surface in vessel $(\mathrm{m})$

$k$ : ratio of horizontal stress to vertical stress $(-)$ 
$k_{1}$ : static value of $k$

$k_{2}$ : dynamic value of $k$

$P$ : powder pressure at depth $h$

$P_{0}$ : powder pressure at $h=0$

$\Delta s$ : shear strain

$\delta_{\mathrm{i}}$ : angle of dynamic internal friction

$\delta_{\mathrm{w}}$ : angle of dynamic wall friction

$\mu_{\mathrm{w}}$ : coefficient of wall friction

$\mu_{\mathrm{wd}}$ : coefficient of dynamic wall friction

$\mu_{\mathrm{ws}}$ : coefficient of static wall friction
$(-) \quad \rho_{\mathrm{B}}$ : aerated bulk density

$\left(\mathrm{kg} / \mathrm{m}^{3}\right)$

(-) $\quad \rho_{\mathrm{P}}$ : particle density

$\left(\mathrm{kg} / \mathrm{m}^{3}\right)$

$(\mathrm{kPa}) \quad \sigma \quad$ : compression stress

$(\mathrm{kPa})$

$(\mathrm{kPa}) \quad \sigma_{1}$ : major principal stress (pre-consolidation stress)

$(-)$

$(\mathrm{kPa})$

(deg) $\tau \quad$ : shear stress

(deg) $\tau_{\mathrm{c}}$ : shear stress at steady state

$(\mathrm{kPa})$

$(-)$

$\tau_{\mathrm{P}}$ : shear stress at plastic equilibrium

$(\mathrm{kPa})$

$(\mathrm{kPa})$

(-) $\phi_{\mathrm{i}}$ : angle of static internal friction

(deg)

(-) $\phi_{\mathrm{w}}$ : angle of static wall friction

\section{References}

1) Janssen, H. A. : Z. Ver dt. Ing., 39, 1045(1895)

2) Walker, D. M. : Chem. Eng. Sci., 21, 975(1966)

3) Walters, J. K. : Chem. Eng. Sci., 28, 131(1973)

4) Hirota, M., T. Kobayashi, O. Sano and
T. Oshima : J. Soc. Powder Technol., Japan, 21, 137 (1984)

5) Konami, M. : Powder Sci. \& Eng., 16, 6, 75(1984) 